\title{
CONTRIBUIÇÕES DOS ESTUDOS ACERCA DA COMPETÊNCIA EM INFORMAÇÃO PARA A CIÊNCIA DA INFORMAÇÃO: UMA ANÁLISE A PARTIR DA PRODUÇÃO CIENTÍFICA DO ENANCIB ENTRE 2015 A 2019
}

\author{
CONTRIBUTIONS FROM STUDIES ON INFORMATION \\ LITERACY TO INFORMATION SCIENCE: AN ANALYSIS \\ FROM ENANCIB SCIENTIFIC PRODUCTION FROM 2015 \\ THROUGH 2019
}

Marta Leandro da Mata ${ }^{a}$

\begin{abstract}
RESUMO
Introdução: No Brasil, a competência em informação tem ganhado cada vez mais espaço no âmbito científico e profissional nas áreas de Biblioteconomia, Ciência da Informação e Arquivologia. No período compreendido entre 2000 a 2019, contabilizamse vinte anos desde o surgimento da primeira de produção acerca da temática no país, tornando-se importante analisar seu impacto neste contexto. Objetivo: Analisar as contribuições da competência em informação para a Ciência da Informação a partir da análise da produção científica dos anais do Encontro Nacional de Pós-Graduação em Ciência da Informação (Enancib) dos últimos cinco anos. De modo mais específico, visa a identificar os termos mais usados para designar a competência em informação, verificar a quantidade de trabalhos acerca da temática por Grupo de Trabalho, identificar as abordagens das pesquisas sobre competência em informação do Enancib a partir dos indicares de competência em informação. Metodologia: Caracteriza-se como uma pesquisa de cunho exploratório e bibliográfico, com abordagem quantitativa e qualitativa. Resultados: as pesquisas sobre a temática têm sido ampliadas ao longo dos anos no Enancib, o termo mais utilizado foi competência em informação; os indicadores que alcançaram uma quantidade significativa de trabalhos foram Colnfo em contextos e abordagens teóricas e Colnfo e bibliotecas, bibliotecários e arquivistas. Conclusões: Observaram-se as abordagens temáticas que precisam ser mais pesquisadas, aquelas que mantêm certa periodicidade e aquelas que, possivelmente, permanecerão sendo discutidas no que tange aos aspectos da competência em informação no Brasil, tendo-se o estado da arte da competência em informação no que diz respeito ao Enancib no período delimitado.
\end{abstract}

Descritores: Competência em Informação. Produção cientifica. Ciência da Informação.

\footnotetext{
a Doutora em Ciência da Informação pela Universidade Estadual Paulista (UNESP). Docente do Departamento de Biblioteconomia e do Programa de Pós-Graduação em Ciência da informação da Universidade Federal do Espírito Santo (UFES). E-mail: martaleandrodamata@gmail.com
} 
Enancib.

\section{INTRODUÇÃO}

No Brasil, a competência em informação tem ganhado cada vez mais espaço no âmbito científico e profissional nas áreas de Biblioteconomia, Ciência da Informação e Arquivologia'. No período compreendido entre 2000 a 2019, contabilizam-se vinte anos desde o surgimento da primeira de produção acerca da temática no país, tornando-se importante analisar seu impacto neste contexto.

A terminologia utilizada para a tradução de Information Literacy para o português é variada: Competência informacional, Letramento informacional, Alfabetização em informação/Informacional, Literacia em Informação, Habilidades informacionais, Competência crítica em Informação e correlatos como Competências Infocomunicacionais.

Mata (2018) observa, a partir de uma análise conceitual realizada por meio de perspectivas teóricas de diversos pesquisadores, que a competência em informação pode ser compreendida por meio de três vieses: a competência em informação como um conjunto de conhecimentos, habilidades e atitudes ligadas ao universo informacional; a competência em informação como um processo de ensino-aprendizagem e a competência em informação como uma área disciplinar.

No primeiro viés, a competência em informação como um conjunto de conhecimentos (saber), habilidades (saber fazer) e atitudes (saber agir) no que tange ao universo informacional, isto é, envolve questões ligadas aos processos informacionais referentes à identificação das necessidades informacionais pelos indivíduos, a busca por fontes de informação em ambientes híbridos (impresso, analógico e digital), avaliação de fontes de informação, de modo a verificar sua confiabilidade, veracidade e credibilidade para fazer uso e comunicá-las quando for necessário. Está ligada ao aprender a aprender e ao aprendizado ao longo da vida.

\footnotetext{
${ }^{1}$ Existem poucos trabalhos na área de Arquivologia acerca da competência em informação, entretanto, nos últimos anos têm ampliado este quantitativo.
} 
No segundo viés, compreende-se a competência em informação como um processo de ensino-aprendizagem acerca do universo informacional, que pode ser ofertado de diversas formas: por meio de programas instrucionais, de disciplinas e atividades presenciais ou à distância realizados pelas bibliotecas e instituições educacionais de acordo suas características e necessidades; idealmente, de modo colaborativo, contando com a participação de bibliotecários, professores, administração e demais envolvidos no ambiente educativo. Uribe Tirado (2009) aponta que estas ações devem ser trabalhadas com uma posição crítica e ética, com diversas fontes de informação em diferentes meios, recursos físicos, eletrônicos ou digitais, explorando as potencialidades (cognitivas, práticas e afetivas) e conhecimentos prévios (outras competências) dos indivíduos.

No terceiro e último, é vista como uma área disciplinar, evidenciada a partir de variadas características, como a existência de padrões/parâmetros, periódicos científicos, seções de associações profissionais ligadas à promoção do tema, eventos científicos e profissionais, declarações acerca da temática e grupos de pesquisa certificados no Conselho Nacional de Desenvolvimento Científico e Tecnológico (CNPq).

Algumas contribuições ocorreram por meio das declarações sobre a competência em informação, realizadas por diversos países, em âmbito nacional e internacional, de modo a instigar as instâncias governamentais, as associações de classe da área, os bibliotecários e demais envolvidos, visando a consolidá-la por meio de ações e programas voltados para toda população. No que tange ao Brasil, foram publicadas a Declaração de Maceió (2011), o Manifesto de Florianópolis (2013) e a Carta de Marília (2014).

Um dos movimentos marcantes são os eventos ocorridos visando a ampliar as discussões, o compartilhamento de experiências, os estudos e as pesquisas em torno da competência em informação, bem como a divulgação do tema entre os cientistas e profissionais da Arquivologia, Biblioteconomia e Ciência da Informação e de áreas correlatas.

No âmbito profissional, foram realizados os Seminários de Competência em Informação, que já estão em sua quinta edição, contando com o apoio de 
diversas instituições, como a Universidade de Brasília (UnB), o Instituto Brasileiro de Informação em Ciência e Tecnologia (IBICT), a Universidade Estadual Paulista (UNESP), a Federação Brasileira de Associações de Bibliotecários, Cientistas de Informação e Instituições (FEBAB).

No âmbito científico, os Seminários de Competência em Informação, que também estão em sua quinta edição, realizados após o Encontro Nacional de Pós-Graduação em Ciência da Informação, com o apoio da Associação Nacional de Pesquisa e Pós-Graduação em Ciência da Informação (ANCIB), com a colaboração do IBCT, UnB, UNESP, Ministério de Ciência, Tecnologia, Inovação e Comunicação (MCTIC).

Outro evento realizado é o Fórum de Competência em Informação, organizado pela rede de Competência em Informação do estado do Rio de Janeiro (formada por representantes da UFRJ, UNIRIO, IBICT, CPII, Fiocruz, rede de bibliotecas de Nova Iguaçu, CPRM); o 1ํ Seminário Internacional de Competência em Informação (I SEICIn) e o 3ํ Seminário de Pesquisas e Práticas sobre Competência em Informação de Santa Catarina (III SEPCIn), por meio do Núcleo de Estudos e Pesquisas sobre Competência em Informação (GPCIn) da Universidade Federal de Santa Catarina, entre outros eventos.

No que se refere à produção em torno da competência em informação, têm-se publicado uma variedade de documentos em âmbito nacional e internacional, pesquisas e relatos de experiência, corroborando para o debate e a troca de informações entre os especialistas, pesquisadores, profissionais e interessados na competência em informação.

Há também estudos voltados para a análise da produção em torno da temática, tendo em vista identificar a quantidade de trabalhos produzidos ao longo do tempo e os assuntos abordados, possibilitando ter um diagnóstico da produção científica e profissional voltada para a competência em informação, identificando temas pouco tratados, emergentes e as tendências de pesquisa.

Neste sentido, esta pesquisa tem como objetivo geral analisar as contribuições da competência em informação para a Ciência da Informação a partir da análise da produção científica dos anais do Encontro Nacional de PósGraduação em Ciência da Informação (Enancib) dos últimos cinco anos. De 
modo mais específico, pretende-se identificar os termos mais usados para designar a competência em informação; verificar a quantidade de trabalhos acerca da temática por Grupo de Trabalho (GT) e identificar as abordagens das pesquisas sobre competência em informação do Enancib a partir dos indicares propostos por Belluzzo (2017).

\section{ABORDAGENS EM TORNO DA COMPETÊNCIA EM INFORMAÇÃO}

A competência em informação envolve os processos informacionais em diferentes aspectos e contextos. Nesta perspectiva, pesquisadoras brasileiras traçaram algumas abordagens que auxiliam a compreender os enfoques dados às pesquisas referentes à temática: Dudziak (2003) aponta três concepções da competência em informação, Vitorino e Piantola (2011) elaboram as dimensões da competência em informação e Belluzzo (2017) delineia treze indicadores para possibilitar a análise da produção científica da competência em informação.

Dudziak (2003) aborda a competência em informação por meio de três concepções fundamentadas na evolução de seu conceito, que apresentam diferentes níveis de complexidade: concepção em informação, concepção em conhecimento e concepção em inteligência. A primeira, a concepção em informação, possui ênfase nas tecnologias de informação e comunicação e está ligada ao processamento e à distribuição da informação com base no desenvolvimento de habilidades de uso das ferramentas e suportes. O foco está no uso de mecanismos eletrônicos.

A segunda, a concepção em conhecimento, possui ênfase nos processos cognitivos; está relacionada à busca de informação para a construção do conhecimento, envolvendo seu uso, interpretação e significado e visa à construção de modelos mentais. Sendo que seu foco está nos indivíduos e em seus processos de compreensão da informação e o uso que fazem deles em situações particulares.

A terceira, a concepção de inteligência, com ênfase no aprendizado ao longo da vida, possui ênfase no aprendizado ao longo da vida; está associada às habilidades e conhecimentos sobre o universo informacional e a valores 
ligados à dimensão social e situacional. Pressupõe-se a incorporação de um estado permanente de mudança, a própria essência do aprendizado como fenômeno. O foco é o indivíduo como ator social e como cidadão (DUDZIAK, 2003).

Piantola e Vitorino (2011) elaboraram quatro dimensões sobre a competência em informação: dimensão técnica, dimensão estética, dimensão ética e dimensão política. A dimensão técnica possui vieses pragmáticos, consiste nas habilidades para encontrar, avaliar e usar a informação. A dimensão estética está ligada à arte que, por sua vez, tem relação com a sensibilidade, criatividade, intuição, harmonia e beleza; refere-se à capacidade de compreender, relacionar, ordenar, configurar e ressignificar a informação. A dimensão ética está relacionada ao cumprimento de leis tendo em vista a vivência em sociedade, com ações que propiciam viver em um determinado contexto, isto é, ao uso responsável da informação. A dimensão política diz respeito à cidadania, aos direitos e deveres dos cidadãos, à sua participação nas decisões e transformações na vida social (VITORINO; PIANTOLA, 2011).

Belluzzo (2017) realizou um estudo que teve como objetivo a criação de uma base teórica e de aplicabilidade da competência em informação. A autora buscou elaborar indicadores visando à análise para a produção científica no que se refere à competência em informação, de modo que possa "[...] oferecer subsídios que permitam a formação de séries temporais que possibilitem visualizar as tendências e perspectivas no tempo, permitir comparações, detectar lacunas e estabelecer necessidades de estudos e pesquisas a partir de uma visão sistêmica do seu estado da arte no contexto nacional." (BELLUZZO, 2017, p. 55). Desta forma, a autora elaborou 13 indicadores que permitem analisar uma atividade científica em torno da competência em informação (Colnfo2), a saber:

2 Colnfo é a sigla para competência em informação no Brasil, cunhada no Seminário de Competência em Informação, realizado na UNESP/Marília, em 2014. 


\section{Quadro 1 - Indicadores de competência em informação}

\begin{tabular}{|c|c|}
\hline $\begin{array}{l}\text { 1) Colnfo e questões } \\
\text { terminológicas }\end{array}$ & $\begin{array}{l}\text { Diz respeito aos termos utilizados para representar a Information } \\
\text { Literacy, isto é, à competência em informação e suas possíveis } \\
\text { traduções e conceitos. }\end{array}$ \\
\hline $\begin{array}{l}\text { 2) Colnfo em contextos } \\
\text { e abordagens teóricas }\end{array}$ & $\begin{array}{l}\text { As propostas teóricas são compreendidas como as principais } \\
\text { abordagens, dimensões, concepções, modelos, padrões, } \\
\text { indicadores, entre outros. }\end{array}$ \\
\hline $\begin{array}{l}\text { 3) Colnfo e políticas e } \\
\text { estratégias }\end{array}$ & $\begin{array}{l}\text { Consideram-se as "[...] diretrizes estabelecidas para a tomada de } \\
\text { decisões nos contextos sociais." (BELLUZZO, 2017, p. 59), bem } \\
\text { como as estratégias traçadas visando a alcançar um objetivo. }\end{array}$ \\
\hline $\begin{array}{l}\text { 4) Colnfo e Inclusão } \\
\text { social e digital }\end{array}$ & $\begin{array}{l}\text { Refere-se às transformações que as Tecnologias de Informação } \\
\text { e Comunicação (TIC) causaram na sociedade e em todos seus } \\
\text { âmbitos, levando-se em consideração as condições econômicas } \\
\text { do país, como seus altos índices de pobreza e analfabetismo. } \\
\text { Neste sentido, busca-se desenvolver ações que agreguem novos } \\
\text { conhecimentos e capacidades nos indivíduos e contribuam para } \\
\text { inovação tecnológica, isto é, ao desenvolvimento econômico do } \\
\text { país. }\end{array}$ \\
\hline $\begin{array}{l}\text { 5) Colnfo no ambiente } \\
\text { de trabalho }\end{array}$ & $\begin{array}{l}\text { Trata-se das habilidades das pessoas para lidar com as fontes de } \\
\text { informação e seus processos como organizar, filtrar e selecionar } \\
\text { informações visando à tomada de decisões no ambiente } \\
\text { organizacional. }\end{array}$ \\
\hline $\begin{array}{l}\text { 6) Colnfo, cidadania e } \\
\text { aprendizado ao longo } \\
\text { da vida }\end{array}$ & $\begin{array}{l}\text { Discorre-se que "A sobrevivência nesse cenário requer aptidão e } \\
\text { o desenvolvimento de habilidades para que o indivíduo seja } \\
\text { capaz de acessar, compreender e fazer melhor uso das } \\
\text { informações disponíveis para o exercício da cidadania e o } \\
\text { aprendizado ao longo da vida." (BELLUZZO, 2017, p. 63). }\end{array}$ \\
\hline $\begin{array}{l}\text { 7) Colnfo e busca e uso } \\
\text { da informação }\end{array}$ & $\begin{array}{l}\text { Refere-se aos processos de busca da informação em diversas } \\
\text { fontes, utilizando os operadores booleanos, os recursos } \\
\text { disponíveis no sistema, bem com o uso ético da informação tendo } \\
\text { como objetivo a construção de conhecimentos, a resolução de } \\
\text { problemas, a tomada de decisões, entre outros. }\end{array}$ \\
\hline $\begin{array}{l}\text { 8) Colnfo } \text { e boas } \\
\text { práticas }\end{array}$ & $\begin{array}{l}\text { Trata-se das práticas de competência em informação realizadas } \\
\text { por diversas instituições e/ou organizações que, por vezes, } \\
\text { culminam no desenvolvimento de modelos, padrões, indicadores, } \\
\text { entre outros que podem servir como exemplo para diversos } \\
\text { profissionais e auxiliar no planejamento e execução de } \\
\text { programas e/ou ações de competência em informação. }\end{array}$ \\
\hline $\begin{array}{l}\text { 9) Colnfo, gestão da } \\
\text { informação, gestão do } \\
\text { conhecimento r e } \\
\text { inteligência competitiva }\end{array}$ & $\begin{array}{l}\text { A Colnfo é aplicada em diversos ambientes. No ambiente } \\
\text { empresarial, possui relação com a gestão da informação e gestão } \\
\text { do conhecimento no que se refere ao desenvolvimento de } \\
\text { competências específicas para lidar com a informação e com o } \\
\text { próprio conhecimento, de modo que propicie a criação da } \\
\text { inteligência de negócios ou inteligência competitiva. }\end{array}$ \\
\hline $\begin{array}{l}\text { 10) Colnfo e bibliotecas, } \\
\text { bibliotecários } \\
\text { arquivistas }\end{array}$ & $\begin{array}{l}\text { Aborda o papel da biblioteca no que se refere à Colnfo e suas } \\
\text { práticas educacionais a respeito do universo informacional e seus } \\
\text { processos. A biblioteca e os bibliotecários podem agir de modo a } \\
\text { compreender o comportamento e as necessidades } \\
\text { informacionais dos indivíduos no que diz respeito à informação, } \\
\text { realizando-se intervenções por meio de ações de Colnfo para } \\
\text { auxiliar os indivíduos no desenvolvimento de suas competências } \\
\text { em informação. Essa questão estende-se aos arquivos e } \\
\text { arquivistas, sendo ainda emergentes os estudos nesta área }\end{array}$ \\
\hline $\begin{array}{l}\text { 11) Colnfo, mídia } \\
\text { tecnologias }\end{array}$ & $\begin{array}{l}\text { Relacionam-se às áreas de informação e comunicação no que diz } \\
\text { respeito às práticas sociais, de forma que possam auxiliar na } \\
\text { produção e compartilhamento do conhecimento individual }\end{array}$ \\
\hline
\end{tabular}

Inf. Inf., Londrina, v. 26, n. 1, p. 232 - 263, jan./mar. 2021. 


\begin{tabular}{|l|l|}
\hline & $\begin{array}{l}\text { coletivo. Trata-se também da aquisição de conhecimentos e } \\
\text { habilidades para lidar com a informação em ambientes híbridos } \\
\text { (tecnológicos, midiáticos e impressos). }\end{array}$ \\
\hline $\begin{array}{l}\text { 12) Colnfo e diferentes } \\
\text { grupos e comunidades }\end{array}$ & $\begin{array}{l}\text { Diz respeito à competência em informação e aos diferentes } \\
\text { grupos e comunidades marginalizados (mulheres, crianças, } \\
\text { idosos, portadores de deficiências, LGBTQIA+ }{ }^{3} \text { ); na possibilidade } \\
\text { de acesso aos recursos informacionais por estes grupos, bem } \\
\text { como na capacidade de usá-los visando à sua inserção e } \\
\text { participação ativa na sociedade, no mercado de trabalho e no } \\
\text { âmbito pessoal. Conforme Belluzzo (2017, p. 69), "[...] a Colnfo é } \\
\text { um fator crítico e condicionante ao desenvolvimento social, } \\
\text { cultural e econômico do Brasil na contemporaneidade [...]". }\end{array}$ \\
\hline $\begin{array}{l}\text { 13) Colnfo, tendências e e } \\
\text { perspectivas }\end{array}$ & $\begin{array}{l}\text { Aborda-se as tendências e perspectivas que propiciam as } \\
\text { transformações sociais em curso e sua relação com a a } \\
\text { competência em informação, bem como as suas possibilidades } \\
\text { de atuação na sociedade. }\end{array}$ \\
\hline
\end{tabular}

Fonte: Belluzzo (2017)

Essas abordagens teóricas sobre as concepções, dimensões e indicadores da competência em informação possuem diversos pontos em comum, observando-se uma expansão de assuntos ao longo do tempo, visto o aumento das pesquisas com ênfase na temática no Brasil. Por sua vez, essas abordagens podem auxiliar no agrupamento de investigações direcionadas a perspectivas específicas, permitindo realizar um levantamento das temáticas mais tratadas no país.

\section{REVISÃO DE LITERATURA DE PUBLICAÇÕES ACERCA DA PRODUÇÃO CIENTÍFICA EM COMPETÊNCIA EM INFORMAÇÃO}

A produção acerca da competência em informação tem sido estudada por alguns pesquisadores no contexto brasileiro, contemplando análise de artigo publicados em períodos, em eventos científicos e profissionais e outras fontes. Diante disso, realizou-se um levantamento destes trabalhos pretendendo mostrar como tem progredido a produção brasileira em torno da temática.

Hatschbach e Olinto (2008) buscaram apresentar uma visão da evolução da Competência em Informação como campo de estudos dentro da Ciência da Informação, com ênfase em trabalhos que se tornaram marcos na área, assim

\footnotetext{
${ }^{3}$ A sigla LGBTQIA+ refere às Lésbicas, Gays, Bissexuais, Transexuais ou Transgêneros, Queer, Intersexo, Assexual e +, que abriga diversas possibilidades de orientação sexual.
} 
como tendências temáticas que têm surgido ao longo do tempo, incluindo o tratamento do tema na América Latina. $\mathrm{O}$ trabalho incluía assuntos referentes à elaboração e implementação de programas educacionais e perspectivas concernentes à época correlacionadas à avaliação de tais programas.

Em suas narrativas, as autoras mencionam a evolução conceitual do tema, abordando o seu surgimento em 19744, o conceito dado pela American Library Association ${ }^{5}$, a relação com o aprendizado baseado em recursos e com a inclusão digital e sobre o aprendizado ao longo da vida. Também constata-se o interesse de outros profissionais pela competência em informação além dos bibliotecários, como professores, psicólogos, coordenadores de curso e diretores. Retomam a Agenda de Pesquisa em Instrução Bibliográfica e Competência em Informação, realizada pela a Association of College \& Research Libraries, nos Estados Unidos 6 .

Discorre-se acerca das terminologias utilizadas por outros países e pelo Brasil, com a predominância do termo Competência em Informação, bem como a produção cientifica em língua espanhola e portuguesa, detectando que neste período são "[...] poucos os trabalhos que tratam de forma integral das habilidades para o acesso e o uso da informação, ou da Competência em Informação." (HATSCHBACH; OLINTO, 2008, p. 24). Destacam-se também a formação de estudantes e os processos avaliativos.

Lecardelli e Prado (2006) realizaram um estudo tendo em vista verificar o estado da arte do tema competência informacional no Brasil, no período de 2001 a 2005, realizando um levantamento bibliográfico por meio dos principais periódicos científicos da área de Ciência da Informação neste período, bem como em teses e dissertações, anais de congressos e livros no âmbito brasileiro.

4 ZURKOWSKI, Paul G. The information service environment relationship and priorities. Washington, D.C: National Commission on Libraries and Information Science, 1974. 30 p.

${ }^{5}$ AMERICAN LIBRARY ASSOCIATION - ALA. Presidential Committee on Information Literacy: final report. Washington, D.C., 1989. Disponível em: http://www.ala.org/ala/mgrps/divs/acrl/publications/whitepapers/presidential.cfm\#importance. Acesso em: 13 jun. 2020.

${ }^{6}$ ASSOCIATION OF COLLEGE AND RESEARCH LIBRARIES. Research Agenda for Library Instruction and Information Literacy. 2003. Disponível em: https://crln.acrl.org/index.php/crlnews/article/view/21643/27137. Acesso em: 27 jun. 2020. 
Estas publicações foram consideradas as precursoras no país.

$O$ enfoque das pesquisas recuperadas foi realizado a partir das concepções propostas por Dudziak (2003), que são: concepção da informação (com ênfase na tecnologia da informação), concepção cognitiva (ênfase nos processos cognitivos) e concepção da inteligência (ênfase no aprendizado). Assim sendo constatou-se que:

O maior percentual da produção científica no Brasil se enquadra na Concepção da Informação, pois seu foco ainda é relacionado à tecnologia da informação, em sua grande maioria os autores associam o tema às questões tecnológicas, de acesso e disponibilização de informações (LECARDELLI; PRADO, 2006, p. 36).

Constataram que se iniciavam os estudos relacionados à concepção cognitiva. Cabe ressaltar que naquele momento havia poucas produções científicas da temática na área, contando com 13 autores, totalizando 19 publicações entre artigos, trabalhos publicados em eventos, livros e teses e dissertações. Destes trabalhos, poucos mencionaram que estavam ligados a projetos sobre a temática, mas daqueles que possuíam, eles estavam em andamento.

Trein e Vitorino (2015) analisam o desenvolvimento da literatura sobre a competência informacional no Brasil no período de 2006 a 2013, dando continuidade ao trabalho de Lecardelli e Prado (2006), por meio da literatura publicada nos periódicos científicos da área e nos eventos Congresso Brasileiro de Biblioteconomia e Documentação, Encontro Nacional de Pesquisa em Ciência da Informação (ENANCIB) e no Seminário Nacional de Bibliotecas universitárias. As autoras também destacaram como motivação esta delimitação temporal devido aos três seminários sobre Competência Informacional apresentados no XXI Congresso Brasileiro de Biblioteconomia, Documentação (CBBD), em 2005, que consideram ter impulsionando o crescimento exponencial da literatura sobre $o$ assunto nos anos que se seguiram.

Os dados foram analisados de modo quantitativo, em que as autoras constataram que as publicações ocorreram em maior quantidade nos eventos, totalizando 121 trabalhos de eventos e 101 artigos de periódicos no período delimitado. Observa-se que "[...] o total de 222 publicações é significativo para o 
período 2006-2013, pois, em média, foram 28 trabalhos publicados anualmente - um número relativamente importante para a temática" (TREIN; VITORINO, 2015, p. 204).

No que se referem às publicações advindas de periódicos científicos, os assuntos abordados variam e não seguem uma escala progressiva, sendo que os anos com maior produção foram de 2006, 2008 e 2009 (cada um com 16 artigos) e 2011 (18 artigos). As autoras supõem que este aumento em 2006 pode ter sido em função da publicação da Declaração de Alexandria em 2005 (revisada pela International Federation of Library Associations and Institutions IFLA em 2008), dos seminários apresentados no XXI CBBD/2005 e da Declaração de Maceió (2011). Já no que se refere aos eventos científicos e profissionais, verificou-se que os anos mais produtivos foram 2009 com 29 publicações, 2011 com 49, e 2013 com 45 (TREIN; VITORINO, 2015).

Leite et al. (2016) analisaram o trabalho e a produção científica referente à competência em informação produzida no principal evento científico da área, - Encontro Nacional de Pesquisa em Ciência da Informação (ENANCIB), organizado pela Associação Nacional de Pesquisa e Pós-Graduação em Ciência da Informação (ANCIB) no período de 1994-2015, com a identificação da inserção do tema no conjunto de seus principais Grupos de Trabalho (GT). A busca foi efetuada junto ao portal de eventos ANCIB - Enancib, com a seleção dos trabalhos relacionados à temática "Competência em Informação" e sete termos correlatos: information literacy (1), competência informacional (2), alfabetização informacional (3), aprendizagem informacional (4), alfabetização em informação (5), letramento informacional (6), educação de usuários (7). Assim, o corpus da pesquisa foi constituído por 3.086 trabalhos (comunicação oral) apresentados nos GT's, tendo-se como principais resultados:

As autoras relatam que somente no IV ENANCIB, em 2000, que houve 0 primeiro registro com a comunicação de Elisabeth Adriana Dudziak, "Information literacy na educação superior: caracterização e conceituação", sendo que este número se repete em 2006 e 2007, nas edições do VII e VIII Enancibs. "A curva é crescente a partir da edição do IX Enancib de 2008 (com quatro trabalhos) até 2010, quando aparecem 13 trabalhos publicados na edição do XI Enancib." 
(LEITE et al., 2016, p. 155). Nos anos de 2011 (XIl Enancib), têm-se sete trabalhos; 2012 (XIII Enancib), 2013 (XIV Enancib) e 2014 (XV Enancib) foram apresentados nove em cada ano; em 2015 (XVI Enancib), treze trabalhos.

No que se referem aos GT's apresentados, constataram que no ano de 2014 o GT3 e GT4 tiveram dois trabalhos publicados em cada, o GT6 teve quatro trabalhos e o GT11 apenas 1. No ano de 2015, o GT3 teve seis apresentações, - GT4 manteve duas, no GT6 diminui pela metade a quantidade de apresentações com três, o GT11 manteve-se com uma (LEITE et al., 2016).

Há uma diversidade de nomenclaturas utilizadas nos textos e na indexação dos trabalhos. Foi possível verificar o uso de termos comuns repetidas vezes para expressar o tema em situações diversas, tais como competência em informação, competência informacional, letramento informacional, aprendizagem informacional, Information Literacy, etc. e, também, expressões novas aportuguesadas ou em outros idiomas, como Media Literacy, Movimento Maker (LEITE et al., 2016, p. 159).

Farias e Farias (2016) realizaram um estudo na coleção Benancib depositada no repositório Questões em Rede, do Grupo de Pesquisa Informação, Discurso e Memória, da Universidade Federal Fluminense, a partir da produção científica do Enancib. Teve-se como objetivo analisar, no período de 2005 a 2014, a recorrência do termo competência e seus desdobramentos do GT6, utilizando-se o método bibliométrico. Como resultados, percebeu-se que as temáticas mais abordadas foram: competência, competência em informação, educação continuada, formação e perfil profissional.

Dudziak (2010) teve como objetivo identificar as tendências de pesquisa em torno da competência informacional, realizando uma busca em duas das principais bases de dados internacionais multidisciplinares dedicadas à análise de citações: Web of Science (WoS) e SCOPUS. A autora apresentou a evolução do conceito de competência informacional, desde sua origem (em 1974) até 2010, apresentando uma análise das tendências mundiais de pesquisa sobre competência em informação.

Observa-se que alguns pesquisadores no âmbito brasileiro procuraram mapear a produção científica em torno da competência em informação, 
pretendendo identificar a evolução no que se refere ao número de trabalhos produzidos no decorrer nos anos, bem como as temáticas abordadas tendo em vista identificar as tendências de pesquisas em determinados períodos. A seguir, serão apresentados os procedimentos metodológicos utilizados nesta pesquisa

\section{PROCEDIMENTOS METODOLÓGICOS}

A presente investigação caracteriza-se como uma pesquisa de cunho exploratório e bibliográfico, com abordagem quantitativa e qualitativa. Inicialmente, realizou-se um levantamento bibliográfico na Base de Dados em Ciência da Informação (BRAPCI) à procura de artigos que discorressem sobre a produção científica e/ou análise bibliométrica acerca da competência em informação; também recorreu-se às referências indicadas nos artigos recuperados em busca de outros materiais que tivessem essa perspectiva.

A partir do exame dos materiais, foi possível verificar a delimitação temporal, abrangência e escopo deles, optando-se por dar sequência ao trabalho de Leite et al. (2016). No presente artigo, realizou-se uma listagem da produção científica acerca da competência em informação dos anais do Enancib dos últimos cinco anos (2015-2019). A escolha pelo Enancib também deve-se por ser o principal evento de pesquisa e pós-graduação da área de Ciência da Informação no Brasil, podendo-se ter uma percepção sobre o estado da arte de temáticas relacionadas à competência em informação com o uso dos indicadores de Belluzzo (2017), tendo-se este aspecto como diferencial. O Enancib é composto por 11 Grupos de Trabalhos (GTs):

\section{Quadro 2 - Temáticas dos Grupos de Trabalho do Enancib}

\begin{tabular}{|l|l|}
\hline $\begin{array}{l}\text { Grupos } \\
\text { Trabalho }\end{array}$ & Tema do Grupo de Trabalho \\
\hline GT 1 & Estudos históricos e Epistemológicos da Ciência da Informação \\
\hline GT 2 & Organização e Representação do Conhecimento \\
\hline GT 3 & Mediação, Circulação e Apropriação da Informação \\
\hline GT 4 & Gestão da Informação e do Conhecimento \\
\hline GT 5 & Política e Economia da Informação \\
\hline GT 6 & Informação, Educação e Trabalho \\
\hline GT 7 & $\begin{array}{l}\text { Produção e Comunicação da Informação em Ciência, Tecnologia e } \\
\text { Inovação }\end{array}$ \\
\hline GT 8 & Informação e Tecnologia \\
\hline
\end{tabular}




\begin{tabular}{|l|l|}
\hline GT 9 & Museu, Patrimônio e Informação \\
\hline GT 10 & Informação e Memória \\
\hline GT 11 & Informação e Saúde \\
\hline
\end{tabular}

Fonte: ANCIB (2020)

Para a coleta e análise de dados utilizou-se a análise de conteúdo de Bardin (2010), que é constituída por três fases, a saber: pré-análise, exploração do material e tratamento, interpretação e inferência dos resultados. Na primeira fase, que corresponde à organização dos materiais, realizou-se análise flutuante visando à seleção dos documentos da pesquisa. Isto é, acessaram-se os anais do Encontro Nacional de Pesquisa em Ciência da Informação por meio dos sites eletrônicos dos eventos realizados entre o período de 2015 a 2019. A maioria deles permanece hospedado nos sites das instituições que promoveram 0 evento ou os anteriores: XVI Enancib - Universidade Federal do Paraíba7, XVII

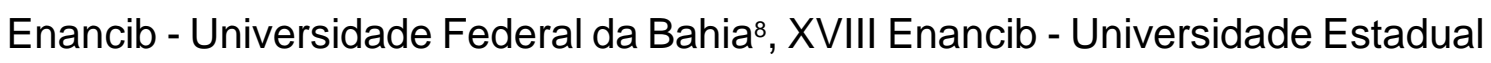
Paulista (UNESP) ${ }^{9}$, XIX Enancib - Universidade Estadual de Londrina ${ }^{10}, \mathrm{XX}$ Enancib Universidade Federal de Santa Catariana"11.

Realizou-se uma busca pelas palavras no título dos trabalhos apresentados nos anais dos eventos: competência em informação, competência informacional, letramento informacional, alfabetização em informação, alfabetização em informação, habilidades informacionais e information literacy. Para ter maior amplitude, verificou-se também pelos termos unitários como competência, letramento, literacia e alfabetização. Selecionaram-se os trabalhos apresentados em formato de comunicação oral e pôster acerca da temática. Também contou-se todos os trabalhos apresentados em cada GT por ano, conforme informações contidas no site dos eventos.

A segunda fase, a exploração do material, foi realizada em dois momentos: 1) a análise dos materiais coletados, organizando-os em quadros contendo a quantidade de trabalhos por GT e aqueles que abarcavam a

\footnotetext{
7 http://www.ufpb.br/evento/index.php/enancib2015/enancib2015/schedConf/presentations

$8 \mathrm{http}: / /$ www.ufpb.br/evento/index.php/enancib2016/enancib2016

${ }^{9} \mathrm{http}: / /$ enancib.marilia.unesp.br/index.php/XVIII_ENANCIB/ENANCIB/schedConf/presentations

$10 \mathrm{http}: / /$ enancib.marilia.unesp.br/index.php/XIX_ENANCIB/xixenancib/schedConf/presentations

11 https://conferencias.ufsc.br/index.php/enancib/2019/schedConf/presentations
} 
temática; 2) realizou-se a leitura do título, resumo e palavras-chave para verificar em quais dos indicadores propostos por Belluzzo (2017) se inseriam. Observase que existia uma categorização pré-estabelecida.

$\mathrm{Na}$ terceira fase, empreendeu-se a análise aprofundada dos materiais, isto é, da produção científica correspondente a cada um dos indicadores (BELLUZZO, 2017) para identificar seus subtemas, visando a fornecer maior informação sobre os assuntos discutidos, realizando-se inferências com base nos resultados e na literatura da área. Desta forma, foi possível verificar as temáticas pouco ou nada trabalhadas, as temáticas emergentes e as tendências de pesquisa acerca da competência em informação no Brasil.

\section{APRESENTAÇÃO E ANÁLISE DOS DADOS}

No Brasil, não há um consenso entre pesquisadores para a tradução do termo Informacion Literacy, visto que é designado de variadas formas. Conforme Belluzzo (2017, p. 57) "[...] a definição do termo ainda traz consigo inúmeras discussões na literatura especializada, tanto nacional quanto internacional". Marzal (2009) agrega a complexidade do conceito e da tradução do termo aos diferentes atores, bem como a distintas épocas e prismas teóricos dados ao longo do tempo. Neste sentido, verificou-se a terminologia utilizada nos anais do Enancib, conforme Quadro 2:

Quadro 3 - Terminologia utilizada nos trabalhos do Enancib 2015-2020

\begin{tabular}{|c|c|}
\hline Termo & Quantidade \\
\hline $\begin{array}{c}\text { Competência em } \\
\text { Informação }\end{array}$ & 61 \\
\hline $\begin{array}{c}\text { Competência } \\
\text { Informacional }\end{array}$ & 13 \\
\hline $\begin{array}{c}\text { Competência Crítica em } \\
\text { Informação }\end{array}$ & 10 \\
\hline Letramento informacional & 6 \\
\hline Information literacy & 5 \\
\hline $\begin{array}{c}\text { Habilidades } \\
\text { informacionais }\end{array}$ & 2 \\
\hline $\begin{array}{c}\text { Alfabetização para a } \\
\text { Informação }\end{array}$ & 1 \\
\hline Total & 98 \\
\hline
\end{tabular}

Fonte: Elaborado pela autora 
A análise foi realizada por meio do título e palavras-chave dos trabalhos, observando-se que, às vezes, um termo é utilizado no título e outro(s) nas palavras-chaves. Nestes casos, especificamente, consideraram-se ambas as terminologias para contabilização. Como resultados, observa-se que o termo com maior predominância é competência em informação. A partir da análise do Overview of information literacy: resources worldwide, de Horton Júnior (2013, 2014/2015), o termo mais indicado para o uso em português do Brasil é competência em informação (BELLUZZO, 2017). Já competência informacional foi o segundo mais utilizado, seguido de competência crítica em informação, information literacy, habilidades informacionais e alfabetização para a informação.

No que tange à competência crítica em informação, o termo surgiu recentemente com uma nova abordagem teórica com viés na teoria crítica.

Quadro 4 - Quantidade de trabalhos apresentados no Enancib por GT entre 20152017 (1)

\begin{tabular}{|c|c|c|c|c|}
\hline $\begin{array}{c}\text { Edição e } \\
\text { data }\end{array}$ & \multicolumn{2}{|c|}{ XVI Enancib/2015 } & \multicolumn{2}{c|}{ XVII Enancib/2016 } \\
\hline GT & $\begin{array}{c}\text { N. de } \\
\text { trabalhos }\end{array}$ & $\begin{array}{c}\text { N. trabalhos de } \\
\text { Colnfo }\end{array}$ & $\begin{array}{c}\text { N. de } \\
\text { trabalhos }\end{array}$ & $\begin{array}{c}\text { N. trabalhos de } \\
\text { Colnfo }\end{array}$ \\
\hline GT 1 & 18 & 1 & 29 & 3 \\
\hline GT 2 & 36 & - & 61 & - \\
\hline GT 3 & 25 & 7 & 29 & 4 \\
\hline GT 4 & 40 & 2 & 32 & - \\
\hline GT 5 & 24 & - & 23 & - \\
\hline GT 6 & 16 & 3 & 22 & - \\
\hline GT 7 & 29 & - & 48 & - \\
\hline GT 8 & 32 & - & 43 & - \\
\hline GT 9 & 22 & - & 18 & - \\
\hline GT 10 & 37 & - & 53 & - \\
\hline GT 11 & 20 & 1 & 19 & $\mathbf{1 2}$ \\
\hline Total & 299 & $\mathbf{1 4}$ & $\mathbf{3 7 7}$ & - \\
\hline
\end{tabular}

Fonte: Elaborado pela autora

No período compreendido entre 2015-2016 teve um total de 26 trabalhos publicados nos Anais do Enancib referindo-se à competência em informação, com uma diferença pouco expressiva quantitativamente, mas ressalta-se o fato de ter diminuído de um ano para o outro, visto que em 2015 foram publicados 14 trabalhos, em 2016 teve 12. No ano de 2015, o GT3 concentrou o maior número de trabalho com 7 (sete), seguido do GT6 com 3 (três), o GT4 com 2 (dois), o 
GT1 e o GT11 tiveram uma produção em cada. Em 2016, foi proporcional o volume de trabalho entre os GT3 e G6, com 5 (cinco) no primeiro, 6 (seis) no segundo e aumentou para 3 (três) no GT1.

Quadro 5 - Quantidade de trabalhos apresentados no Enancib por GT entre 20152017 (2)

\begin{tabular}{|c|c|c|c|c|c|c|}
\hline $\begin{array}{c}\text { Edição } \\
\text { e data }\end{array}$ & \multicolumn{2}{|c|}{ XVIII Enancib/2017 } & \multicolumn{2}{c|}{ XIX Enancib/ 2018 } & \multicolumn{2}{c|}{ XX Enancib/2019 } \\
\hline GT & $\begin{array}{c}\text { N. de } \\
\text { trabalhos }\end{array}$ & $\begin{array}{c}\text { N. } \\
\text { trabalhos } \\
\text { de Colnfo }\end{array}$ & $\begin{array}{c}\text { N. de } \\
\text { trabalhos }\end{array}$ & $\begin{array}{c}\text { N. } \\
\text { trabalhos } \\
\text { de Colnfo }\end{array}$ & $\begin{array}{c}\text { N. de } \\
\text { trabalhos }\end{array}$ & $\begin{array}{c}\text { N. } \\
\text { trabalhos } \\
\text { de Colnfo }\end{array}$ \\
\hline GT 1 & 27 & 2 & 29 & 2 & 27 & - \\
\hline GT 2 & 65 & - & 51 & - & 60 & - \\
\hline GT 3 & 37 & 6 & 53 & 11 & 50 & 6 \\
\hline GT 4 & 46 & 4 & 62 & 1 & 82 & 1 \\
\hline GT 5 & 32 & 2 & 45 & - & 41 & 1 \\
\hline GT 6 & 22 & 4 & 25 & 5 & 48 & 13 \\
\hline GT 7 & 57 & - & 45 & - & 41 & - \\
\hline GT 8 & 44 & - & 48 & - & 47 & - \\
\hline GT 9 & 19 & - & 31 & - & 38 & - \\
\hline GT10 & 27 & - & 45 & 1 & 35 & - \\
\hline GT11 & 16 & 2 & 12 & 1 & 23 & - \\
\hline Total & $\mathbf{3 9 2}$ & $\mathbf{2 0}$ & $\mathbf{4 4 6}$ & $\mathbf{2 1}$ & $\mathbf{4 9 2}$ & $\mathbf{2 1}$ \\
\hline
\end{tabular}

Fonte: Elaborado pela autora

Entre 2017-2019 contabilizaram-se 62 trabalhos, mantendo-se um regularidade na quantidade de produções científicas por ano. Em 2017, o GT3 concentrou maior quantidade de publicações com 6 (seis), o GT4 e o GT6 manteve 4 (quatro) em cada, o GT1, GT5 e o GT11 obtiveram 2 (duas) em cada. Em 2018, ressalta-se que o GT3 deteve 11 publicações acerca da temática, seguido do GT6 com 5 (cinco), o GT1 com 2 (duas), o GT4, GT10 e o GT11 tiveram uma em cada. Em 2019, houve um aumento significativo de trabalhos no GT6 com 13, o GT3 com 6 (seis) e os GT4 e GT5 contou com um em cada.

Ao todo foram 88 trabalhos de competência em informação ao longo destes cinco anos, sendo que, a partir de 2017, a quantidade de trabalhos dobra em relação ao ano anterior, permanecendo praticamente desta forma até 2019. A partir dos resultados, constata-se que são o GT3 e o GT6 que reúnem a maior parte das publicações científicas sobre competência em informação do Enancib consecutivamente. A seguir é apresentado o Quadro 6, contendo os trabalhos organizados por categorias (indicadores). 
Quadro 6 - Trabalhos científicos analisados por meio dos indicadores de Belluzzo (2017) e por ano de publicação no ENANCIB

\begin{tabular}{|c|c|c|c|c|c|c|}
\hline Indicadores & 2015 & 2016 & 2017 & 2018 & 2019 & $\begin{array}{l}\text { Total por } \\
\text { Indicador }\end{array}$ \\
\hline $\begin{array}{l}\text { 1) Colnfo e } \\
\text { questões } \\
\text { terminológicas }\end{array}$ & - & - & - & 1 & - & 1 \\
\hline $\begin{array}{l}\text { 2) Colnfo em } \\
\text { contextos e } \\
\text { abordagens } \\
\text { teóricas }\end{array}$ & 3 & 3 & 2 & 7 & 5 & 20 \\
\hline $\begin{array}{l}\text { 3) Colnfo e } \\
\text { políticas e } \\
\text { estratégias }\end{array}$ & - & - & - & - & - & - \\
\hline $\begin{array}{l}\text { 4) Colnfo e } \\
\text { Inclusão social e } \\
\text { digital }\end{array}$ & 1 & 1 & 2 & - & 1 & 5 \\
\hline $\begin{array}{l}\text { 5) Colnfo no } \\
\text { ambiente de } \\
\text { trabalho }\end{array}$ & 2 & - & 2 & - & - & 4 \\
\hline $\begin{array}{l}\text { 6) Colnfo, } \\
\text { cidadania e } \\
\text { aprendizado ao } \\
\text { longo da vida }\end{array}$ & - & - & 2 & - & - & 2 \\
\hline $\begin{array}{l}\text { 7) Colnfo e busca e } \\
\text { uso da informação }\end{array}$ & 2 & 2 & 3 & 2 & 3 & 12 \\
\hline $\begin{array}{l}\text { 8) Colnfo e boas } \\
\text { práticas }\end{array}$ & 1 & - & 1 & 2 & 2 & 6 \\
\hline $\begin{array}{l}\text { 9) Colnfo, gestão } \\
\text { da informação, } \\
\text { gestão do } \\
\text { conhecimento e } \\
\text { inteligência } \\
\text { competitiva }\end{array}$ & - & - & 3 & 1 & - & 4 \\
\hline $\begin{array}{l}\text { 10) Colnfo e } \\
\text { bibliotecas, } \\
\text { bibliotecários e } \\
\text { arquivistas }\end{array}$ & 4 & 5 & 3 & 3 & 5 & 20 \\
\hline $\begin{array}{l}\text { 11) Colnfo, mídia e } \\
\text { tecnologias }\end{array}$ & - & - & 1 & 2 & 2 & 5 \\
\hline $\begin{array}{l}\text { 12) Colnfo e } \\
\text { diferentes grupos } \\
\text { ou comunidades }\end{array}$ & 1 & - & 1 & 3 & 2 & 7 \\
\hline $\begin{array}{l}\text { 13) Colnfo, } \\
\text { tendências e } \\
\text { perspectivas }\end{array}$ & - & 1 & - & - & 1 & 2 \\
\hline Total & & & & & & 88 \\
\hline
\end{tabular}

Fonte: Elaborado pela autora

Observou-se que não houve nenhum trabalho no indicador 3) Colnfo e políticas e estratégias. Há uma lacuna neste âmbito devido à ausência de políticas públicas que incentivem a implementação de programas de competência em informação nas instituições educacionais. Diversas declarações 
acerca da competência em informação abordam essa questão: a Declaração de Alexandria (INTERNATIONAL..., 2008, p. 1-2) convoca as "[...] as organizações governamentais e inter-governamentais a buscarem políticas e programas que promovam a competência informacional e o aprendizado ao longo da vida; na Declaração de Maceió (2011, p. 1) "As bibliotecas e outras instituições relacionadas com a informação devem estabelecer parcerias para ações estratégicas e políticas públicas envolvendo o sistema de educação obrigatória.". Outras declarações e manifestos também apontam essa necessidade (MANIFESTO DE FLORIANÓPOLIS, 2013; CARTA DE MARÍLIA, 2014).

No indicador 1) Colnfo e questões terminológicas houve um trabalho, que discorre sobre a semântica e pragmática do termo. A Information Literacy foi traduzida de diversas formas no contexto brasileiro, permanecendo com a utilização de suas variáveis nos trabalhos do Enancib, com predominância de competência em informação, conforme visto no Quadro 1. Conforme Gasque (2010), os conceitos e terminologias, embora inter-relacionados, possuem diferenças, justificando que não devem ser empregados como sinônimos, na medida em que representam ações, eventos e ideias distintas. Belluzzo (2017) acredita que um termo deva ser utilizado para representá-la no país, facilitando inclusive nos processos de recuperação das informações relacionadas à temática e a diminuição de ambiguidades. Considera-se que há uma necessidade de reflexão sobre este aspecto pelos pesquisadores da área, visando à ampliação das discussões sobre a terminologia a ser fixada no Brasil, se assim houver necessidade.

Nos indicadores a seguir houve dois trabalhos para cada um deles: 6) Colnfo, cidadania e aprendizado ao longo da vida e 13) Colnfo, tendências e perspectivas. Os trabalhos apresentados no indicador seis, ambos no ano de 2017, mostraram as seguintes perspectivas: o primeiro era sobre competência crítica em informação, ética intercultural e cidadania global na era digital; e o segundo era sobre dados abertos, competência crítica em informação e cidadania. Nos resultados obtidos por Leite et al. (2016), que fizeram uma análise dos trabalhos do Enancib por categorias, no período compreendido entre 2010 e 2013, observa-se que ocorreram poucas produções sobre essa temática, com 
frequência $(2,72 \%)$. Infere-se que há necessidade de publicações acerca dos aspectos referentes à cidadania, visto sua importância nas discussões emergentes.

O indicador 13) Colnfo, tendências e perspectivas contém dois trabalhos utilizando o método denominado bibliometria. O primeiro, publicado em 2016, com uma análise do termo "competência" no GT6 do Enancib; infere-se que o GT6 teve um recorde de trabalhos sobre a temática em 2019, além de manter uma produção contínua referindo-se ao tema. O segundo, publicado em 2019, em formato pôster, apresenta uma análise inicial sobre a produtividade autoral referente à competência em informação na América Latina. Estes trabalhos trazem algumas tendências de pesquisas acerca da temática nos últimos anos, possibilitando aos pesquisadores terem uma percepção dos enfoques dados nos estudos nestes âmbitos.

Os indicadores 5) Colnfo no ambiente de trabalho e 9) Colnfo, gestão da informação, gestão do conhecimento e inteligência competitiva tiveram quatro publicações em cada. O quinto indicador, Colnfo no ambiente de trabalho, trata das habilidades das pessoas para lidar com as fontes de informação, que podem auxiliá-las na tomada de decisões no ambiente organizacional (BELLUZZO, 2017). Neste sentido, ocorreu a concentração de trabalhos nos anos de 2015 e 2017, com as seguintes temáticas: dois foram referentes à televisão universitária, um sobre a competência informacional em ambientes de trabalho e um sobre a análise da transição do prontuário físico para o eletrônico.

O nono indicador 9) Colnfo, gestão da informação, gestão do conhecimento e inteligência competitiva contempla trabalhos com abordagens em torno da competência em informação e a gestão do conhecimento; competência em informação para a construção de conhecimento no processo decisório; estudos voltados para o perfil de gestores de micro e pequenas corretoras de seguros com enfoque na competência em informação; e sobre a competência organizacional e competência em informação em uma organização. Leite et al. (2016) expõem que ocorreu poucas contribuições para essa temática entre 2010 e 2013 no Enancib, com 2,72\%.

Os indicadores a seguir contêm cinco produções científicas em cada: 4) 
Colnfo e Inclusão social e digital e 11) Colnfo, mídia e tecnologias. No que se refere ao quatro, Colnfo e Inclusão social e digital, visa a que toda população possa participar ativamente na sociedade, com trabalhos direcionados à inclusão digital no Projeto Um Computador por Aluno do Ceará; inclusão de pessoas com deficiências; inclusão digital, competência em informação e literacias digitais; competência em informação e análise ético-política da desigualdade social; competência em informação no projeto LUCES.

Ressalta-se que, além do acesso à informação, é necessário que os indivíduos saibam como localizar, avaliar a credibilidade, confiabilidade e autenticidade da informação, bem como fazer uma análise crítica de suas características e funcionalidades, compreendendo seus usos no que tange aos aspectos sociais, políticos, econômicos, possibilitando maior emancipação na sociedade. Essa questão está em consonância com a agenda da Organização das Nações Unidas (ONU), Transformando Nosso Mundo: A Agenda 2030 para o Desenvolvimento Sustentável, mas especificamente, com o Objetivo 10. Reduzir a desigualdade dentro dos países e entre eles (ORGANIZAÇÃO..., 2015).

O indicador 11) Colnfo, mídia e tecnologias diz respeito às áreas de informação e comunicação, acerca das práticas sociais no que tange à produção e compartilhamento de informações de modo individual e coletivo (BELLUZZO, 2017). Os trabalhos possuem os seguintes assuntos: competência informacional e midiática; competência crítica em informação e Fake News; competência em informação, Fake News e marco civil da internet; avaliação da informação e de Fake News; competência crítica em informação e big data.

No contexto atual, ressalta-se o uso de várias redes e mídias sociais, que permitem a interação entre os usuários em ambientes virtuais, além de diversos recursos disponíveis como, por exemplo, o Facebook, Instagram, Twitter, entre outros. Essas redes sociais podem ser usadas como forma de informar ou desinformar. Enfatiza-se a veiculação de informações de caráter falso, isto é, as denominadas Fake News ou desinformação, divulgadas propositalmente, de modo a causar danos em diversas esferas sociais, políticas, sanitárias, culturais, entre outros. Neste sentido, existem cinco trabalhos publicados a partir de 2017 
correlacionando a competência em informação: três abordam Fake News, competências informacionais e midiáticas e um acerca da temática e big data.

Neste indicador, 8) Colnfo e boas práticas, com seis trabalhos, discorrese sobre ações e/ou programas que tiveram êxito nos aspectos referentes ao seu planejamento, implementação e execução pelas instituições que o aderiram, assim sua divulgação é importante para a comunidade da área para que possam ter exemplos para se basearem. Os trabalhos referentes a essa temática abordaram os ambientes virtuais de aprendizagem para a promoção da competência em informação; a construção de um framework para a educação profissional e tecnológica; a promoção de competências infocomunicacionais para o ensino médio; a competência em informação e a biblioteca voltada para o ensino fundamental; competência em informação e projetos interdisciplinares e aprendizagens; e competências em informação na Web. Contudo, infere-se que é uma quantidade reduzida para o contexto brasileiro, visto que há uma carência de programas e ações voltadas para a competência em informação em nível macro, de modo formal ou informal. Considera-se que para sua consolidação no cenário nacional, é necessário maior disseminação entre os profissionais bibliotecários acerca da temática, com ênfase nos aspectos conceituais, metodológicos e práticos. Ressalta-se que também é importante realizar a distinção entre as atividades ligadas à educação de usuários e à competência em informação, fazer ampla divulgação de parâmetros de âmbito nacional e internacional, elaborar e disponibilizar materiais didáticos e estender as discussões por meio de instituições e associação de classe da área.

O indicador 12) Colnfo e diferentes grupos ou comunidades aborda as comunidades marginalizadas/vulneráveis, que são compreendidas como:

[...] aquelas se encontram em situações de discriminação, intolerância e fragilidade e que estão em desigualdade e desvantagem na sociedade atual, principalmente, em relação às questões que envolvem o acesso e uso da informação para a construção de conhecimento, identidade e autonomia a fim de permitir a sua efetiva inclusão social (MANIFESTO DE FLORIANÓPOLIS, 2013, p. 1).

Neste indicador, houve sete trabalhos, com maior quantidade a partir de 2018, com os seguintes temas: dois acerca de competência em informação e 
idosos; dois sobre competência em informação e pessoas trans; um abordando a competência em informação e comunidade rurais; um a respeito da competência crítica em informação e mulheres negras; e um voltado para pais de crianças e adolescentes surdos. É de suma importância os trabalhos voltados para grupos considerados marginalizados na sociedade, auxiliando em seus processos de inserção social, política, econômica, profissional e pessoal, isto é, a emancipação dos indivíduos e seu bem-estar social. Essa questão é mencionada na Declaração de Alexandria (INTERNATIONAL..., 2008, p. 2) que enfatiza que se devem realizar "[...] programas para incrementar as capacidades de empregabilidade e empreendedorismo das mulheres e dos menos favorecidos, incluindo imigrantes, sub-empregados e desempregado", bem como na Agenda 2030 (ORGANIZAÇÃO..., 2015).

Houve 12 trabalhos no indicador 7) Colnfo e busca e uso da informação, pois visam a compreender o nível de desenvolvimento da competência em informação de grupos e comunidades. As publicações anuais neste indicador mantêm uma continuidade ao longo do período delimitado nesta pesquisa, sendo que quatro trabalhos possuíam enfoque voltados para profissionais de determinadas áreas (jurídica, pedagogia e saúde); três abrangiam treinamento e educação de usuários e a competência em informação; dois eram sobre a competência em informação e narrativa acerca dos contadores de história; dois sobre o letramento informacional em âmbitos escolares acadêmicos (Instituto Federal de Sergipe e Universidade de Brasília) e um sobre a iniciação cientifica e o desenvolvimento da competência em informação. Leite et al. (2016) observam que teve uma ocorrência de $48 \%$ de trabalhos voltados para diferentes grupos/comunidades, abrangendo as áreas de áreas de saúde, direito, docentes de ensino superior, biblioteconomia, crianças, professores de educação básica e empresarial, no período compreendido entre 2010 e 2013, do Enancib. Observa-se que é essencial a realização deste tipo análise visando a compreender quais são as habilidades já adquiridas, as que precisam ser aprimoradas e aquelas que necessitam ser desenvolvidas nos indivíduos, isto é, tem-se um diagnóstico acerca das competências em informação dos indivíduos. A partir disso, torna-se possível desenvolver ações e/ou programas de 
competência em informação voltados para suas especificidades.

$\mathrm{O}$ indicador 2) Colnfo em contextos e abordagens teóricas, obteve uma das maiores quantidades de trabalhos voltados para a temática, com 20 publicações. Trata-se de questões fundamentais para o amadurecimento e consolidação da competência em informação no Brasil, visto que se referem às principais abordagens, dimensões, concepções, modelos, padrões, indicadores, envolvendo áreas e teorias correlatas (BELLUZZO, 2017).

Neste sentido, três trabalhos contemplavam assuntos referentes aos parâmetros (mapeamento de modelos, padrões e documentos; modelos na educação profissional; diretrizes para idosos), dois sobre leitura (interseções e interlocuções entre leitura e competência em informação; relações entre a ética em informação, a leitura e a competência em informação). Houve um trabalho acerca de cada um destes assuntos: competência crítica em informação e vigilância e filtragem de conteúdo nas redes digitais; letramento informacional, crescimento e democracia; Information Literacy no Brasil, rede conceitual e rede virtual de aprendizagem; mapa do conhecimento da Ciência da Informação de Zins para a competência em informação; competência crítica em informação e participação ética em comunidades de aprendizagem; abordagem fenomenográfica da competência em informação; competência em informação e Educação; arquivologia e competência em informação; estudo comparativo do conceito de competência; competência em informação e ansiedade de informação; conceitos de capacidade de absorção e competência em informação; teoria crítica aos estudos sobre regime de informação e competência crítica em informação; contribuições freireanas para os estudos de competência crítica da informação; competência científica, competência em informação e midiática; competência em informação no contexto educacional.

$\mathrm{O}$ indicador 10) Colnfo e bibliotecas, bibliotecários e arquivistas alcançou uma quantidade significativa de trabalhos, perfazendo um total de 20 , com resultado identifico ao indicador dois. A maioria deles, com 10 publicações, acerca dos atributos e da atuação do bibliotecário em relação à competência em informação em diversos tipos de instituições e ambientes (em hospitais universitários, em institutos federais, em biblioteca escolar, em associações 
profissionais, no processo de mediação em universidades, na Rede de Bibliotecas das Unidades de Pesquisa, no processo de autoarquivamento em repositórios institucionais, através do uso da metacognição para o desenvolvimento de ações e a partir das dimensões da competência em informação); três sobre a formação do bibliotecários em diversos vieses (por meio de um panorama curricular, por meio do olhar dos professores que ministram disciplinas acerca da temática, acerca das habilidades informacionais e as crenças de autoeficácia); quatro a respeito dos ações em bibliotecas (análise das práticas educacionais em biblioteca universitárias, análise da formação de usuários em uma biblioteca universitária, biblioteca como organização aprendente e a competência em informação, e o letramento informacional e a relação da biblioteca escolar e a sala de aula); dois sobre Arquivologia (um estudo teórico de revisão e um sobre a formação e a competência em informação); e um referente às contribuições da competência em informação para a atuação em preservação de arquivistas e bibliotecários). Leite et al. (2016) discorrem que, em sua análise, no período entre 2010 e 2013 , na categoria bibliotecas, voltadas para as instituições públicas e universitárias, com ênfase no papel do bibliotecário e da competência em informação nesses cenários, teve uma produção de $12,8 \%$.

Sendo o bibliotecário o protagonista na implementação e divulgação entre os membros da instituição dos aspectos inerentes aos programas de competência em informação, é fundamental que ocorram pesquisas direcionadas para a sua formação e atuação profissional no que diz respeito à temática. Muitas declarações mencionam a necessidade de que os currículos do curso de Biblioteconomia abarquem a temática, bem como seja ampliada a discussão em cenário nacional a partir do apoio por meio das instituições e associações de classe da área de Biblioteconomia e Ciência da Informação (DECLARAÇÃO DE TOLEDO, 2006; MANIFESTACIÓN DE PARAMILLO, 2010; DECLARAÇÃO DE MACEIÓ, 2011; DECLARAÇÃO DE HAVANA, 2012, MANIFESTO DE FLORIANÓPOLIS, 2013). Verificam-se também que as discussões voltadas para os arquivistas e arquivos são ainda recentes, mas têm se ampliado. 
De modo geral, este estudo buscou trazer um diagnóstico, com base no período delimitado, em relação às produções científicas do Enancib acerca da competência em informação, identificando em quais GT estão concentradas, bem como uma análise de sua abordagem temática, conforme os indicadores de Belluzzo (2017). Conforme a Declaração de Havana (2012, p. 2), há uma necessidade de obtenção de diagnósticos atualizados para verificar o estado da arte da competência em informação em diversos contextos, de modo que seja possível "[...] identificar e avaliar níveis de desenvolvimento e linhas de ação para avançar no tema".

\section{CONSIDERAÇÕES FINAIS}

Neste momento em que a competência em informação completa vinte anos no Brasil, com a realização de diversos eventos, de produções de viés científico, profissional e publicação de diversos documentos - parâmetros e declarações - torna-se necessário compreender sua dimensão no que diz respeito aos dados quantitativos e suas abordagens temáticas.

Neste sentido, a presente pesquisa buscou verificar como tem sido a produção científica em torno da temática no Enancib nos últimos cinco anos, verificando-se que houve um aumento considerável na quantidade de trabalhos enviados para o evento, principalmente a partir de 2017. Este fator demonstra que há um conjunto de aspectos para o crescimento de pesquisadores interessados na competência em informação, como por exemplo, debates em torno de eventos, grupos de pesquisa, entre outros.

Os GT que mais contribuíram com publicações sobre a temática foram o GT 3 - Mediação, Circulação e Apropriação da Informação e o GT 6 - Informação, Educação e Trabalho. Nos outros GT houve trabalhos em menor quantidade, porém quase que ininterruptamente, como: o GT 1 - Estudos históricos e Epistemológicos da Ciência da Informação, GT 4 - Gestão da Informação e do Conhecimento, GT 5 - Política e Economia da Informação, e GT 11- Informação e Saúde, também existiram trabalhos, mas em menor quantidade. No GT 10 Informação e Memória só teve um trabalho em 2018. 
A terminologia mais utilizada é competência em informação, principalmente nos últimos anos do evento, destacando-se as recomendações realizadas por Belluzzo (2017), visando à centralização de um termo que não haja ambiguidades semânticas, dificultando sua compreensão. Também discorre-se que os termos competência informacional, competência crítica em informação, letramento informacional, Information Literacy e alfabetização para a informação são utilizados, mas em menor número de vezes.

Por fim, identificaram-se as abordagens temáticas que foram mais discutidas na literatura científica do evento. Neste sentido, identificou-se que a maioria delas está inserida no indicador 2) Colnfo em contextos e abordagens teóricas, no 10) Colnfo e bibliotecas, bibliotecários e arquivistas, voltados para a formação e, principalmente, a atuação do profissional bibliotecário e no 7) Colnfo e busca e uso da informação. Estes estudos fortalecem a temática em território nacional, no viés teórico, prático e metodológico.

A temática está em ascensão no indicador 4) Colnfo e Inclusão social e digital, 11) Colnfo, mídia e tecnologias, 8) Colnfo e boas práticas e 12) Colnfo e diferentes grupos ou comunidades. Esses indicadores fazem alusão a assuntos essenciais para o desenvolvimento da sociedade, trabalhando-se com grupos ou comunidades, com a inclusão das pessoas nesta sociedade por meio do uso de diversas informações, visando à compreensão de suas características finalidades, bem como com a divulgação das melhores práticas para que deem subsídios para que instituições e profissionais possam realizá-las em seus locais de atuação. Acredita-se que essas temáticas permanecerão sendo discutidas em pesquisas atuais e futuras acerca da competência em informação.

No que se refere aos indicadores 5) Colnfo no ambiente de trabalho e 9) Colnfo, gestão da informação, gestão do conhecimento e inteligência competitiva, acredita-se que são temas que devem ser mais explorados pelos pesquisadores da área. Eles referem-se às organizações, empresas, entre outros, visando ao aprimoramento de habilidades informacionais dos indivíduos para o fortalecimento de ações no que tange aos processos informacionais e à integração em aspectos relacionados à gestão, possibilitando maior comunicação entre os colaboradores e melhorias no âmbito organizacional. As 
questões ligadas às organizações estão correlacionadas ao desenvolvimento econômico do país.

Os indicadores 6) Colnfo, cidadania e aprendizado ao longo da vida, 1) Colnfo e questões terminológicas 3) Colnfo e políticas e estratégias foram pouco abordados, necessitando da ampliação dos debates em torno desses assuntos. No indicador 13) Colnfo, tendências e perspectivas mostrou-se nos trabalhos que continham análises bibliométricas que tinham por finalidade identificar as tendências de discussões acerca da competência em informação.

Assim, recomenda-se que estudos visando à compreender as abordagens temáticas e o nível de produção em torno da competência em informação continuem sendo realizados no Enancib, com ampliação para os eventos da área de Arquivologia, Biblioteconomia e Ciência da Informação, bem como em outros tipos de publicações advindas de teses e dissertações e de artigos na esfera nacional.

\section{AGRADECIMENTOS}

Agradeço às bolsistas de iniciação científica (PIIC/Ufes) Gabriela Maria de Jesus e Julia Schettino Jacob dos Santos pela colaboração na coleta de dados.

\section{REFERÊNCIAS}

ASSOCIAÇÃO NACIONAL DE PESQUISA E PÓS-GRADUAÇÃO EM CIÊNCIA DA IFNORMAÇÃO (ANCIB). Grupos de trabalho (GTs). Disponível em: http://www.enancib2019.ufsc.br/gts/. Acesso em: 25 mar. 2020

BARDIN, L. Análise de conteúdo. 4. ed. Lisboa: Edições 70, 2010.

BELLUZZO, R. C. B. O estado da arte da competência em informação (COINFO) no Brasil: das reflexões iniciais à apresentação e descrição de indicadores de análise. Revista Brasileira de Biblioteconomia e Documentação, São Paulo, v. 13, n. especial, p. 47-76, jan./jul. 2017.

CARTA DE MARÍLIA. In: SEMINÁRIO DE COMPETÊNCIA EM INFORMAÇÃO: CENÁRIOS E TENDÊNCIAS. 3., 2014, Marília-SP. Anais... Marília-SP: UNESP; UNB; IBICT, 2014. Disponível em: 
http://gicio.valentim.pro.br/data/documents/Carta_de_Marilia_Portugues_Final.p df. Acesso em 27 jun. 2020.

DECLARAÇÃO DE HAVANA: 15 ações de competência em informação/ ALFIN. 2012. Disponível em: https://www.ifla.org/files/assets/informationliteracy/publications/Declaration/Compet.Declara-de-Havana.2012.PortuBrasil.pdf. Acesso em: 15 jun. 2020.

DECLARAÇÃO DE MACEIÓ sobre a competência informacional. In: CONGRESSO BRASILEIRO DE BIBLIOTECONOMIA, DOCUMENTAÇÃO E CIÊNCIA DA INFORMAÇÃO, 24., 2011. Maceió: FEBAB; IBICT; UnB, 2011. Disponível em: http://febab.org.br/declaracao_maceio.pdf. Acesso em: 15 jun. 2020.

DECLARAÇÃO DE TOLEDO SOBRE ALFABETIZAÇÃO INFORMACIONAL. In: SEMINÁRIO DE TRABALHO "BIBLIOTECA, APRENDIZAJE Y CIUDADANÍA: LA ALFABETIZACIÓN INFORMACIONAL", 2006. Anais[...] Toledo: 2006.

DUDZIAK, E. A. Competência informacional: análise evolucionária das tendências da pesquisa e produtividade científica em âmbito mundial. Informação \& Informação, Londrina, v. 15, n. 2, p. 1-22, 2010.

DUDZIAK, E. A. Information Literacy: princípios, filosofia e prática. Ciência da Informação, Brasília, v. 32, n. 1, p. 23-35, jan./abr. 2003.

FARIAS, G. B.; FARIAS, M. G. G. Estudo bibliométrico das publicações do gt6 - enancib: análise do termo competência.In: ENCONTRO NACIONAL DE PESQUISA EM CIÊNCIA DA INFORMAÇÃO, 17., 2016, Salvador. Anais [...] Salvador, BA: ANCIB; PPGCI/UFBA, 2016.

GASQUE, K. C. G. D. Arcabouço teórico do letramento informacional. Ciência da Informação, Brasília, v. 39, n. 3, p. 83-92, 2010.

HATSCHBACH, M. H. L.; OLINTO, G. Competência em informação: caminhos percorridos e novas trilhas. Revista Brasileira de Biblioteconomia e Documentação, Nova Série, São Paulo, v.4, n.1, p. 20-34, jan./jun. 2008.

INTERNATIONAL FEDERATION OF LIBRARY ASSOCIATIONS AND INSTITUTIONS. Declaração de Alexandria sobre competência informacional e aprendizado ao longo da vida. Revisado em 2008. Disponível em: https://www.ifla.org/files/assets/wsis/Documents/beaconinfsocpt.pdf. Acesso em: 14 fev. 2020

LECARDELLI, J.; PRADO, N. S. Competência informacional no Brasil: um estudo bibliográfico no período de 2001 a 2005. Revista Brasileira de Biblioteconomia e Documentação: Nova Série, São Paulo, v. 2, n. 2, p. 21 46, dez. 2006. Disponível em: https://rbbd.febab.org.br/rbbd/article/view/16. Acesso em: 27 jun. 2020. 
LEITE, C.; SIMEÃO, E. L. M. S.; NUNES, E. M. A.; BRANCO, F. C.; FERES, G. G.; FREIRE, I. M.; BELLUZZO, R. C. B. Cenário e perspectiva da produção científica sobre competência em informação (Colnfo) no Brasil: estudo da produção no âmbito da ANCIB. Inf. \& Soc.: Est., João Pessoa, v. 26, n. 3, p. 151-168, set./dez. 2016. Disponível em: https://periodicos.ufpb.br/ojs2/index.php/ies/article/view/31983. Acesso em: 27 jun. 2020.

MANIFESTO DE FLORIANÓPOLIS sobre a competência em informação e as populações vulneráveis e minorias. 2013. In: CONGRESSO BRASILEIRO DE BIBLIOTECONOMIA, DOCUMENTAÇÃO E CIÊNCIA DA INFORMAÇÃO, 25., 2011. Florianópolis: FEBAB; IBICT; UnB; UNESP, 2011.

MANIFESTACIÓN de Paramillo. In: COLOQUIO INTERNACIONAL SOBRE TECNOLOGÍAS APLICADAS A LOS SERVICIOS DE INFORMACIÓN. 10., 2010, San Cristóvan. Anais [...] San Cristóvan: ANABISAI; UNET, 2010. Disponível em: http://alfinenargentina.blogspot.com/2011/08/venezuelamanifestacion-sobre-alfin-de.html. Acesso em: 27 jun. 2020.

MARZAL, M. A. Evolución conceptual de la alfabetización en información a partir de la alfabetización múltiple en su perspectiva educativa y bibliotecaria. Investigación Bibliotecológica, v. 23, n. 47, p. 129-160, abr. 2009. Disponível em: http://www.scielo.org.mx/scielo.php?script=sci_abstract\&pid=S0187358X2009000100006\&lng=es\&nrm=iso. Acesso em: 27 jun. 2020

MATA, M. L. M. Competência em informação: questões terminológicas e conceituais. In: GERLIM, M. N. M. (Org.). Competência em informação e narrativa numa sociedade conectada por redes. Brasília: Faculdade de Ciência da Informação, Universidade de Brasília, 2018. 364 p. (Coleção No balanço das redes: tradição e tecnologia, v. 2). Disponível em: https://repositorio.unb.br/handle/10482/32703. Acesso em: 18 maio 2020

ORGANIZAÇÃO DAS NAÇÕES UNIDAS. Transformando nosso mundo: a agenda 2030 para o desenvolvimento sustentável. Nova lorque: ONU, 2015. Disponível em: https://nacoesunidas.org/pos2015/agenda2030/. Acesso em: 20 abr. 2020.

TREIN, J. M.; VITORINO, E. V. A evolução da temática competência em informação no Brasil: um estudo bibliográfico no período de 2006 a 2013.

Revista Brasileira de Biblioteconomia e Documentação, v. 11, p. 190-210, 2015. Disponível em: https://rbbd.febab.org.br/rbbd/article/view/416. Acesso em: 27 jun. 2020.

URIBE TIRADO, A. Interrelaciones entre veinte definicionesdescripciones del concepto de alfabetización en propuesta de macro-definición. ACIMED, Havana, v. 20, n. 4, p. 1-22, 2009. Disponível em: http://scielo.sld.cu/scielo.php?script=sci_arttext\&pid=S102494352009001000001. Acesso em: 27 jun. 2020. 
VITORINO; E. V.; PIANTOLA, D. Dimensões da competência informacional (2). Ciência da Informação, v. 40 n. 1, p. 99- 110, jan./abr., 2011.

\title{
CONTRIBUTIONS FROM STUDIES ON INFORMATION LITERACY TO INFORMATION SCIENCE: AN ANALYSIS FROM ENANCIB'S SCIENTIFIC PRODUCTION BETWEEN 2015 THROUGH 2019
}

\begin{abstract}
Introduction: In Brazil, the Information Literacy has gained more and more space in the scientific and professional scope in the areas of Library Science, Information Science and Archivology. In the period from 2000 to 2019, twenty years have passed since the first production about the theme appeared in the country, making it important to analyze its impact in this context. Objective: This research has as general objective to analyze the contributions of the information literacy for the Information Science from the analysis of the scientific production of the annals of the National Meeting of Post-Graduation in Information Science (Enancib) of the last five years. More specifically, it aims to identify the most used terms to designate information literacy, to verify the amount of work on the theme by Working Group, to identify the approaches to research on competence in information from Enancib from the indicators in information literacy. Methodology: It is characterized as an exploratory and bibliographic research, with a quantitative and qualitative approach. Results: Research on the subject has been expanded over the years at Enancib, the most used term was information literacy; the indicators that achieved a significant amount of work were information literacy in theoretical contexts and approaches and Colnfo and libraries, librarians and archivists. Conclusions: We observed the thematic approaches that need to be further researched, those that maintain a certain periodicity, since they help in the maturation and consolidation of the theme and those that, possibly, will continue to be discussed regarding the aspects of information literacy in the country, having or state of the art to offer information in what it says respect to the period not limited.
\end{abstract}

Descriptors: Information Literacy. Scientific Production. Information Science. Enancib.

\section{CONTRIBUCIONES DE LOS ESTUDIOS SOBRE ALFABETIZACIÓN INFORMACIONAL PARA LAS CIENCIAS DE LA DOCUMENTACIÓN: ANÁLISIS DE LA PRODUCCIÓN CIENTÍFICA DE ENANCIB ENTRE 2015 Y 2019}

\section{RESUMEN}

Introducción: En Brasil, la alfabtización informacional ha ganado cada vez más espacio en los campos científico y profesional en las áreas de Información e Documentación, Ciencia de la Documentación y Archivología. En el período comprendido entre 2000 y 2019, se han contado veinte años desde el surgimiento de la primera producción sobre 
el tema en el país, por lo que es importante analizar su impacto en este contexto. Objetivo: Esta investigación tiene como objetivo general analizar las contribuciones de la alfabetización informacional a las Ciencias de la Documentación a partir del análisis de la producción científica de los anales del Encuentro Nacional de Estudios de Posgrado en Ciencias de la Información (Enancib) de los últimos cinco años. Más concretamente, tiene por objeto identificar los términos más utilizados para designar la alfabetización informacional, verificar la cantidad de trabajos sobre el tema por Grupo de Trabajo, identificar los enfoques de la investigación sobre alfabetización informacional de Enancib a partir de los indicadores de alfabetización informacional indica. Metodología: Se caracteriza por ser una investigación exploratoria y bibliográfica, con un enfoque cuantitativo y cualitativo. Resultados: La investigación sobre el tema se ha ampliado a lo largo de los años en Enancib, el término más utilizado fue la competencia en información; Los indicadores que lograron una cantidad significativa de trabajo fueron Colnfo en contextos teóricos y enfoques y Colnfo y bibliotecas, bibliotecarios y archiveros. Conclusiones: observamos los enfoques temáticos que deben seguir investigando, aquellos que mantienen una cierta periodicidad, ya que ayudan en la maduración y consolidación del tema, y los que, posiblemente, seguirán siendo discutidos con respecto a aspectos de competencia en información en el país, que tienen o están a la vanguardia para ofrecer información en lo que disse respecto al período no limitado.

Descriptores: Alfabetización informacional. Producción científica. Ciencias de la Documentación. Enancib.

Recebido em: 30.06.2020

Aceito em: 08.02.2021 